\title{
Short Term Economic Emission Power Scheduling of Hydrothermal Energy Systems Using Improved Water Cycle Algorithm
}

\author{
SHAIKH SAAQIB HAROON, AND TAHIR NADEEM MALIK* \\ RECEIVED ON 09.09.2015 ACCEPTED ON 11.05.2016
}

\begin{abstract}
Due to the increasing environmental concerns, the demand of clean and green energy and concern of atmospheric pollution is increasing. Hence, the power utilities are forced to limit their emissions within the prescribed limits. Therefore, the minimization of fuel cost as well as exhaust gas emissions is becoming an important and challenging task in the short-term scheduling of hydro-thermal energy systems. This paper proposes a novel algorithm known as WCA-ER (Water Cycle Algorithm with Evaporation Rate) to inspect the short term EEPSHES (Economic Emission Power Scheduling of Hydrothermal Energy Systems). WCA has its ancestries from the natural hydrologic cycle i.e. the raining process forms streams and these streams start flowing towards the rivers which finally flow towards the sea. The worth of WCA-ER has been tested on the standard economic emission power scheduling of hydrothermal energy test system consisting of four hydropower and three thermal plants. The problem has been investigated for the three case studies (i) ECS (Economic Cost Scheduling), (ii) ES (Economic Emission Scheduling) and (iii) ECES (Economic Cost \& Emission Scheduling). The results obtained show that WCA-ER is superior to many other methods in the literature in bringing lower fuel cost and emissions.
\end{abstract}

Key Words: Economic Emission Scheduling, Multi-objective Optimization, Water Cycle Algorithm, Evaporation Rate, Fuel Emissions, Exhaust Gas Emissions

\section{INTRODUCTION}

$\mathrm{T}$

The problem of economic power scheduling of all thermal plants [1,2] and EPSHES (Economic Power Scheduling of Hydrothermal Energy Systems) has been solved for last many years due to the huge importance. The EPSHES is basically to determine the optimal amount of water for the hydropower plants and the power output from the thermal plants in a specified horizon so as to minimize the total cost of electrical energy. The solution of EPSHES involves many constraints of the hydropower and thermal plants including cascade nature of hydropower plants, varying reservoir inflows, limits of the reservoir storage, limits on the discharge capacity, water transport delay, the prohibited discharge zones of

* Department Electrical Engineering, University of Engineering \& Technology, Taxila.

Mehran University Research Journal of Engineering \& Technology, Volume 36, No. 2, April, 2017 [p-ISSN: 0254-7821, e-ISSN: 2413-7219] 
hydropower plants, multiple valve point effects on thermal fuel cost curves, ramp rates of thermal plants, the varying load demand, and the limitations on the generation by the hydropower and thermal plants[3]. The problem of EPSHES reduces to only minimize the fuel cost of thermal plants as the generation cost of hydropower plants is insignificant. But due to the implementation of clean energy act and zero emission regulations, the problem of EPSHES has been transformed into EEPSHES, which includes the minimization of exhaust gas emissions in addition to the minimization of total fuel cost. The problem of short term EEPSHES is the most vital problem in the power system operation which controls the total production cost by deciding the share of thermal energy due to the unavailability of hydropower at a specified interval of time. This thermal energy is also responsible for the exhaust gas emissions making the EEPSHES as multiobjective optimization problem which is more complex and complicated to solve as compared to a single objective optimization problem of EPSHES. Therefore, both the problems of minimizing fuel cost and fuel emissions are solved simultaneously in EEPSHES using three case studies (i) ECS (ii) EES and (iii) ECES. As both these objectives are of contradictory nature to each other, hence a cost penalty method has been proposed to find a trade-off between these two contradictory objectives.

In the developed countries, due to the vitality of the environmental concerns, EEPSHES problem is being extensively investigated and it is under active research due to stronger needs of economical operating schedules.

Several methods have been proposed and discussed in [4] to reduce the exhaust gas emission levels of thermal plants. These exhaust gas emissions may be taken as an objective function in economic dispatch problem. Besides them various other techniques such as Fuzzy Satisfaction
Decision Approach [5], Improved Back-Propagation Neural Network [6], Maximizing Decision Recursive Technique [7], Multi-objective Approach using Evolutionary Algorithm [8], Improved GA (Genetic Algorithm) [9,10], PSO (Particle Swarm Optimization) [11,12], DE (Differential Evolution) [13,14] and Gravitational Search Algorithm [15,16] have been previously applied to reduce the emissions.

In this paper an improved form of WCA, known as WCA-ER presented by Sadollah, et. al. [17] has been used to solve the non-linear and non-convex EEPSHES problem. This algorithm has its ancestries from the water cycle process of the nature that how the rain process forms streams and these streams flow towards rivers and then these rivers finally drops into sea. The performance of WCA-ER was compared with GA, PSO and $\mathrm{DE}$ for several bench mark constrained optimization problems and WCA-ER was found out to be superior than these [17]. The WCA-ER has not yet been investigated to solve the problem of power system operation. In the proposed work, short-term hydrothermal scheduling problem has been investigated using WCA-ER while taking into account the non-convexity of thermal plants' fuel cost characteristics that arise due to valve point effect. The effectiveness of WCA-ER has been tested on a standard test system of EEPSHES problem for different cases.

The contribution of the proposed work is, the highly nonconvex and complex problem of EEPSHES has completely been modelled for the environment of WCA-ER and a complete algorithm has been developed whose parameters have effectively been tuned so as to achieve the optimum results for all the three cases of ECS, EES and ECES. The comparison of the results with other strong techniques shows that WCA-ER has been successful in finding lower fuel costs and lesser exhaust gas emissions in all the three cases. 


\section{MATHEMATICAL FORMULATION OF EEPSHES PROBLEM}

Mathematically, the objective function and constraints for EEPSHES problem are formulated as follows:

\subsection{Economic Cost Scheduling}

The objective of pure ECS (Economic Fuel Cost Scheduling) problem is the minimization of total fuel cost of thermal plants. Mathematically it is represented as [3]:

$\operatorname{minimize~} \mathrm{F}=\sum_{\mathrm{t}=1 \mathrm{x}=1}^{\mathrm{M}} \sum_{\mathrm{s}}^{\mathrm{N}_{\mathrm{x}}} \mathrm{f}_{\mathrm{x}}\left(\mathrm{PG}_{\mathrm{sxt}}\right)$

where, $\mathrm{F}$ is the total fuel cost, $\mathrm{f}_{\mathrm{x}}$ is the fuel cost of $\mathrm{xth}$ thermal plant, $\mathrm{PG}_{\mathrm{sxt}}$ is the power generation of $\mathrm{xth}$ thermal generating unit at time t,M are the total number of time intervals for the scheduled period and $\mathrm{N}_{\mathrm{s}}$ are the total number of thermal plants.

The objective function of both convex and non-convex nature will be handled in this research work:

\subsubsection{Convex Objective Function}

Conventionally, the fuel cost function of thermal plants can be represented as a quadratic function as follows:

$f_{x}\left(P_{s x t}\right)=a_{x} P G_{s x t}^{2}+b_{x} P G_{s x t}+c_{x}$

where, $a_{x}, b_{x}, c_{x}$ are the fuel cost coefficients of $x$ th thermal plant.

\subsubsection{Non-Convex Objective Function}

For the precise and real-world modeling of problem, the above mentioned fuel cost function needs to be reviewed. The real-world characteristics involve valve point effect and the objective function is re-written as:

$\mathrm{f}_{\mathrm{x}}\left(\mathrm{PG}_{\mathrm{sxt}}\right)=\mathrm{a}_{\mathrm{x}} \mathrm{PG}_{\mathrm{sxt}}^{2}+\mathrm{b}_{\mathrm{x}} \mathrm{PG}_{\mathrm{sxt}}+\mathrm{c}_{\mathrm{x}}+\left|\mathrm{d}_{\mathrm{x}} * \sin \left\{\mathrm{g}_{\mathrm{x}}\left(\mathrm{PG}_{\mathrm{sx}}^{\min }-\mathrm{PG}_{\mathrm{sxt}}\right)\right\}\right|$ where, $d_{x}, g_{x}$ are the fuel cost coefficients of $x$ th thermal plant showing valve point effect.

\subsection{Economic Emission Scheduling}

The EES problem is to minimize the amount of exhaust gas emissions from thermal plants due to burning of fossil fuels used for generation of electricity. The emission released by thermal plant can be formulated as summation of an exponential function with a quadratic one [8]. The EES problem is written mathematically as:

$$
\operatorname{minimize} \mathrm{E}=\sum_{\mathrm{t}=1 \mathrm{x}=1}^{\mathrm{M}} \sum_{\mathrm{s}}^{\mathrm{N}_{\mathrm{s}}} \mathrm{e}_{\mathrm{xt}}\left(\mathrm{PG}_{\mathrm{sxt}}\right)
$$

where, $\mathrm{E}$ is the total fuel emissions, and $\mathrm{e}_{\mathrm{xt}}$ are the total amount of exhaust gases released by xth thermal plant.

$\mathrm{e}_{\mathrm{xt}}\left(\mathrm{PG}_{\mathrm{sxt}}\right)=\alpha_{\mathrm{sx}} \mathrm{PG}_{\mathrm{sxt}}^{2}+\beta_{\mathrm{sx}} \mathrm{PG}_{\mathrm{sxt}}+\gamma_{\mathrm{sx}}+\eta_{\mathrm{sx}} \exp \left(\rho_{\mathrm{sx}} \mathrm{PG}_{\mathrm{sxt}}\right)$

where, $\alpha_{x}, \beta_{x}, \gamma_{x}, \eta_{x}, \rho_{x}$ are the emission coefficients of $x$ th thermal plant.

\subsection{Economic Cost and Emission Scheduling}

The mutual ECES problem seeks a trade-off relation between exhaust gas emissions and fuel cost. Emission scheduling is incorporated in pure economic dispatch problem by adding emission cost in conventional cost scheduling. This becomes a multi-objective ECES problem, converted into a single one by introducing a cost penalty approach as follows [6]:

$\operatorname{Min} \mathrm{TC}=\sum_{\mathrm{t}=1 \mathrm{x}=1}^{\mathrm{M}} \sum_{\mathrm{s}}^{\mathrm{s}_{\mathrm{s}}}\left[\mathrm{f}_{\mathrm{xt}}\left(\mathrm{PG}_{\mathrm{sxt}}\right)+\mathrm{CPF}_{\mathrm{t}} * \mathrm{e}_{\mathrm{xt}}\left(\mathrm{PG}_{\mathrm{sxt}}\right)\right]$

The trade-off relation between fuel cost and exhaust gas emission is developed as:

Min TC $=\sum_{\mathrm{t}=1 \mathrm{x}=1}^{\mathrm{M}} \sum_{\mathrm{s}}^{\mathrm{s}_{\mathrm{s}}}\left[\mathrm{K}_{\mathrm{xt}} * \mathrm{f}_{\mathrm{xt}}\left(\mathrm{PG}_{\mathrm{sxt}}\right)+\mathrm{K}_{2} * \mathrm{CPF}_{\mathrm{t}} * \mathrm{e}_{\mathrm{xt}}\left(\mathrm{PG}_{\mathrm{sxt}}\right)\right]$

where, $\mathrm{CPF}_{\mathrm{t}}$ cost penalty factor at time interval $t$ and $\mathrm{K}_{1}$, $\mathrm{K}_{2}$ are the weight factors. 
The route of finding the cost penalty factors is given below:

(i) Compute the average production cost and average exhaust gas emission of each generating plant at its maximum rated power.

(ii) Obtain the ratio $h_{\mathrm{sx}}$ by dividing the computed average production cost with the average emission according to following equation. The numerator and the denominator of the Equation (8) are the formulae for calculating the average production cost and the average exhaust gas emissions respectively.

$\mathrm{h}_{\mathrm{sx}}\left(\frac{\$}{l b}\right)=\frac{F\left(P G_{s x}^{\max } / P G_{s x}^{\max }\right)}{E\left(P G_{s x}^{\max } / P G_{s x}^{\max }\right)}$ Re-arrange the computed values of $h_{s x}$ in an ascending order.

Starting from the smallest $\mathrm{h}_{\mathrm{sx}}$ add max loading limit of each generating unit one at a time until $\Sigma \mathrm{PG}_{\mathrm{sx}}{ }^{\max } \geq \mathrm{PD}_{\mathrm{t}}$ is achieved.

At this phase, $h_{\mathrm{sx}}$ related with last unit is the cost penalty factor $\mathrm{CPF}_{\mathrm{t}}$ for a given power demand at time $t$.

From above procedure it is obvious that the value of cost penalty factor $\mathrm{CPF}_{t}$ depends on the power demand during each interval $t$ and it varies according to power demand.

\subsection{Constraints}

The above described objective functions are to be minimized subject to various hydraulic and thermal constraints [3], which can be written mathematically as:

\subsubsection{Power Balance Constraint}

The total hydropower and thermal generations at each time interval $t$ should meet the forecasted load demand.

$\sum_{y=1}^{N_{h}} P_{h y t}+\sum_{x=1}^{N_{s}} P_{s x t}=P_{t}$

where, $\mathrm{PG}_{\mathrm{hyt}}$ is the generated power of yth hydropower unit at interval t, $\mathrm{PD}_{\mathrm{t}}$ is the power demand at interval $\mathrm{t}$ and $\mathrm{N}_{\mathrm{h}}$ is the total number of hydropower plants

The power generated by the hydropower plant involves the storage volume of reservoir and discharge rate of water and it is expressed as:

$\mathrm{PG}_{\text {hyt }}=\mathrm{A}_{\text {ly }} \mathrm{U}_{\text {hyt }}^{2}+\mathrm{A}_{2 \mathrm{y}} \mathrm{U}_{\text {hyt }}^{2}+\mathrm{A}_{3 \mathrm{y}} \mathrm{U}_{\text {hy }} \mathrm{D}_{\text {hyt }}+\mathrm{A}_{4 \mathrm{y}} \mathrm{U}_{\text {hyt }}+\mathrm{A}_{5 \mathrm{j}} \mathrm{D}_{\text {hyt }}+\mathrm{A}_{6 \mathrm{y}}$

where, $A_{1 y}, A_{2 y}, A_{3 y}, A_{4 y}, A_{5 y}, A_{6 y}$ are the generation coefficients of yth hydropower plant, $\mathrm{U}_{\text {hyt }}$ is the reservoir storage volume of yth plant at time $t$ and $\mathrm{D}_{\text {hyt }}$ is the water release of yth plant at time $t$.

\subsubsection{Generation Capacity Constraint}

$$
\begin{aligned}
& \mathrm{PG}_{\mathrm{sx}}^{\min }<\mathrm{PG}_{\mathrm{sxt}}<\mathrm{PG}_{\mathrm{sx}}^{\max } \\
& \mathrm{PG}_{\mathrm{hy}}^{\text {min }}<\mathrm{PG}_{\mathrm{hyt}}<\mathrm{PG}_{\mathrm{hy}}^{\text {max }}
\end{aligned}
$$

where, $\mathrm{PG}_{\mathrm{sx}}{ }^{\min }, \mathrm{PG}_{\mathrm{sx}}{ }^{\max }$ are the minimum \& maximum generating capacity of $\mathrm{xth}$ thermal plant and $\mathrm{PG}_{\mathrm{hy}}{ }^{\mathrm{min}}$, $\mathrm{PG}_{\mathrm{sy}}{ }^{\max }$ are the minimum \& maximum generation capacity of yth hydropower plant.

\subsubsection{Discharge Rate Limit}

$\mathrm{D}_{\text {hy }}^{\min }<D_{\text {hyt }}<\mathrm{D}_{\text {hy }}^{\max }$

where, $\mathrm{D}_{\text {hy }}^{\text {min }}, \mathrm{D}_{\text {hy }}^{\text {max }}$ are the minimum and maximum discharge limits of yth reservoir.

Mehran University Research Journal of Engineering \& Technology, Volume 36, No. 2, April, 2017 [p-ISSN: 0254-7821, e-ISSN: 2413-7219] 


\subsubsection{Reservoir Volume Storage Constraint}

$\mathrm{U}_{\text {hy }}^{\min }<U_{\text {hy }}<\mathrm{U}_{\text {hy }}^{\max }$

where, $\mathrm{U}_{\text {hy }}{ }^{\text {min }}, \mathrm{U}_{\text {hy }}$ max are the minimum \& maximum reservoir storage limits of yth reservoir.

\subsubsection{Water Balance Constraint}

$\mathrm{U}_{\text {hyt }}=\mathrm{U}_{\text {hy, },-1}+\ln \mathrm{F}_{\text {hyt }}-\mathrm{D}_{\text {hyt }}-\mathrm{S}_{\text {hyt }}+\sum_{\mathrm{n}=1}^{\mathrm{R}_{\mathrm{uy}}}\left(\mathrm{D}_{\mathrm{hn}, \mathrm{t}-\tau_{\mathrm{ny}}}+\mathrm{S}_{\mathrm{hn}, \mathrm{t}-\tau_{\mathrm{ny}}}\right)$

where, $\operatorname{lnf}_{\text {hyt }}$ is the natural inflow of yth hydropower plant respectively at time $t, \mathrm{~S}_{\text {hyt }}$ is the spillage discharge rate of yth hydropower plant respectively at time $t, \mathrm{R}_{\mathrm{uy}}$ is the number of upstream hydropower generating units immediately above the yth reservoir and $\tau_{\text {ny }}$ is the water transport time delay from reservoir $\mathrm{n}$ to reservoir $\mathrm{y}$.

\subsubsection{Reservoir End Conditions}

$$
\mathrm{U}_{\mathrm{y}}^{0}=\mathrm{U}_{\mathrm{y}}^{\ln }, \mathrm{U}_{\mathrm{y}}^{\mathrm{M}}=\mathrm{U}_{\mathrm{y}}^{\mathrm{End}} ; \mathrm{y}=1,2, \ldots . . \mathrm{N}_{\mathrm{h}}
$$

where, $\mathrm{U}_{\mathrm{y}}^{\text {lni }}, \mathrm{U}_{\mathrm{y}}^{\text {End }}$ are the initial \& final reservoir volume storage restrictions of yth reservoir.

The Equations (11-16) are the constraints. The constraints need to be satisfied for all the variables. After each step; initialization of variables and calculation of other variables, these constraints are repeatedly checked and satisfied. These equations are used to confirm whether the initialized variables and the calculated variables are within their prescribed limits. All these variables must satisfy these constraints mentioned in Equations (11-16).

\section{WATER CYCLE ALGORITHM WITH EVAPORATIONS RATE}

\subsection{Basic Concept}

WCA-ER mimics the natural water cycle as formation of streams from rain and then their flow towards rivers and then flow of these rivers towards the sea. The first step is the assumption of rain so that a population of streams is generated randomly.

\subsection{Initialization}

A population of design variables i.e. the population of streams is initially generated randomly. The individual having the best fitness value i.e. the best stream is chosen as sea and some next as rivers. The remaining streams flow towards rivers and sea [17]. Initially $\mathrm{N}_{\text {pop }}$ streams are created. Each stream created is a candidate solution. The total population of stream as mentioned in [17] is:

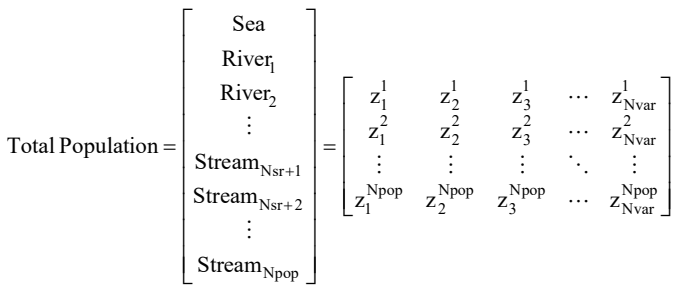

The stream having the lowermost value is marked as the sea. $\mathrm{N}_{\mathrm{sr}}$ (a predefined parameter) is the sum of a sea and total of number of rivers as per Equation (18). The remaining number of streams $\mathrm{N}_{\text {stream }}$ might start flowing towards the rivers or directly towards the sea will be calculated as per Equation (19) as follows:

$\mathrm{N}_{\mathrm{sr}}=$ Number of Rivers +1 (Sea)

$\mathrm{N}_{\text {stream }}=\mathrm{N}_{\text {pop }}-\mathrm{N}_{\text {sr }}$

The sea absorbs the water from river and every river absorbs the water from the streams. Some streams will might directly flow towards the sea as well. The intensity of flow of streams determines the amount of water entering a specific river or sea depends. The number of streams entering the sea and the no. of streams entering the river are calculated using the Equation (20). 


$$
\mathrm{NS}_{\mathrm{n}}=\operatorname{round}\left\{\left|\frac{\mathrm{CV}_{\mathrm{n}}}{\sum_{\mathrm{x}=1}^{\mathrm{N}_{\mathrm{sr}}} \mathrm{CV}_{\mathrm{x}}}\right| \times \mathrm{N}_{\text {stream }}\right\}, \mathrm{n}=1,2,3, \ldots . ., \mathrm{N}_{\mathrm{sr}}
$$

Where $\mathrm{CV}_{\mathrm{n}}$ is the fitness value or the cost function. The absolute sign is used to eliminate the negative sign and round operator is used because any value other than positive integers cannot be assigned to a river or sea. e.g. 1.5 or 1.7 streams flow to the river.

\subsection{Movement of Streams to the Rivers or Sea}

Fig. 1 [17] but modified\& redrawn) shows a stream flowing towards a specific river. The connection lines are also shown. The distance $\mathrm{Z}$ between the river and the stream is updated as:

$\mathrm{Z} \in(0, \mathrm{C} x$ dist $), \mathrm{C}>1$

The value of $\mathrm{C}$ is such that, $1 \leq \mathrm{C} \leq 2$, and the finest value for $\mathrm{C}$ may be 2; is the distance between stream and river. Keeping $\mathrm{C}>1$ bounds streams to flow in various directions towards rivers. Same concept is also used to indicate rivers flowing towards the sea [17]. The latest positions of streams, rivers and sea are given using the following equations:

$$
\begin{aligned}
& Z_{\text {stream }}^{\mathrm{i}+1}=\mathrm{Z}_{\text {stream }}^{\mathrm{i}}+\operatorname{rnd} \times \mathrm{C} \times\left(\mathrm{Z}_{\text {River }}^{\mathrm{i}}-\mathrm{Z}_{\text {stream }}^{\mathrm{i}}\right) \\
& \mathrm{Z}_{\text {stream }}^{\mathrm{i}+1}=\mathrm{Z}_{\text {stream }}^{\mathrm{i}}+\operatorname{rnd} \times \mathrm{C} \times\left(\mathrm{Z}_{\text {sea }}^{\mathrm{i}}-\mathrm{Z}_{\text {stream }}^{\mathrm{i}}\right) \\
& \mathrm{Z}_{\text {River }}^{\mathrm{i}+1}=\mathrm{Z}_{\text {River }}^{\mathrm{i}}+\operatorname{rnd} \times \mathrm{C} \times\left(\mathrm{Z}_{\text {sea }}^{\mathrm{i}}-\mathrm{Z}_{\text {River }}^{\mathrm{i}}\right)
\end{aligned}
$$

where, rnd is a uniformly distributed random number between 0 and 1. Equation (22) depicts streams flowing towards the corresponding river and Equation (23) depicts streams flowing directly towards the sea. If the fitness of the streams comes out to be better than its connecting rivers then the streams and river is swapped with each other. The same is done for the river and sea.

\subsection{Evaporation and Raining Process}

In the evaporation process sea water vaporizes as the streams or rivers flow towards the sea. This results in rainfall to form new streams. It is therefore checked if the rivers or streams have advanced up to the sea to make the evaporation process occur [17]. This avoids premature convergence of this algorithm. The following condition is used to check this evaporation condition:

Case $1\left\|\mathrm{Z}_{\text {sea }}^{\mathrm{x}}-\mathrm{Z}_{\text {River }}^{\mathrm{x}}-1\right\|<$ dist $_{\text {max }}$ or rnd $<0.1, \mathrm{x}=1,2,3, \ldots . . \mathrm{N}_{\mathrm{sr}}-1$

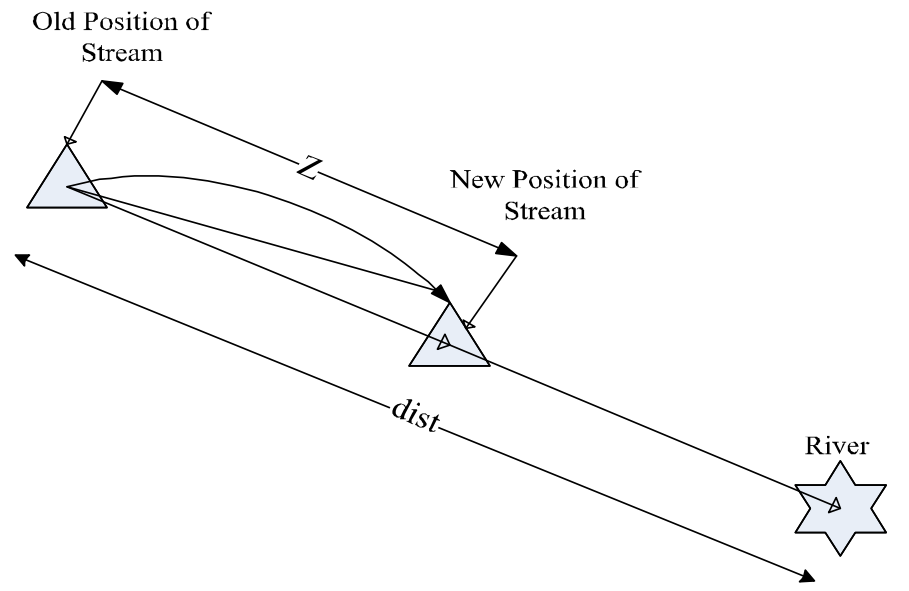

FIG. 1. GRAPHICAL VIEW OF STREAM FLOWING TOWARDS A RIVER (TAKEN FROM [17] AND RE-DRAWN) 
if the above condition in Case 1 becomes true then start the raining process as per Equation (25), where dist ${ }_{\max }$ is a small number (very near to zero).

$Z_{\text {stream }}^{\text {new }}=\operatorname{Min} \operatorname{Lim}+\operatorname{rnd} \times(\operatorname{Max} \operatorname{Lim}-\operatorname{Min} \operatorname{Lim})$

The same condition of evaporation is checked for those streams which start flowing directly to the sea. The condition for evaporation for the streams directly flowing towards the sea is:

Case $2\left\|Z_{\text {sea }}^{\mathrm{x}}-\mathrm{Z}_{\text {Stream }}^{\mathrm{x}}-1\right\|<$ dist $_{\max }, \mathrm{x}=1,2,3, \ldots . . \mathrm{NS}_{1}$

If the above condition in Case 2 becomes true, then start the raining process as per Equation (26):

$$
Z_{\text {stream }}^{\text {new }}=Z_{\text {sea }}+\sqrt{\sigma} \times \operatorname{rndn}(1, N)
$$

where, $\sigma$ depicts the area being searched around the sea. After the evaporation the created streams with $\sigma$ variance are disseminated around the sea. $\operatorname{mndn}(1, \mathrm{~N})$ is a vector of $\mathrm{N}$ standard Gaussian numbers. The smaller $\sigma$ helps to search in minor region near the sea. The optimized value of $\sigma$ is found to be 0.1 [17].

The value of dist ${ }_{\max }$ is calculated from Equation (27) and is decreasing adaptively. If a higher value of dist ${ }_{\text {max }}$ is selected it avoids extra searches and its smaller value intensify the search closer to the sea.

$$
\operatorname{dist}_{\text {max }}^{\mathrm{i}+1}=\operatorname{dist}_{\text {max }}^{\mathrm{i}}-\frac{\text { dist }_{\text {max }}^{\mathrm{i}}}{\text { Max Itration }}
$$

This raining process is analogous to mutation in GA.

The streams and rivers which have low flow intensity and are not able to reach the sea will definitely evaporate after some time. The evaporation process in WCA-ER is altered slightly by adding the concept of evaporation rate[17]. Therefore, the evaporation rate $(\varepsilon)$ is defined as:

$$
\varepsilon=\left\{\frac{\sum_{\mathrm{n}=2}^{\mathrm{N}_{\mathrm{sr}}} \mathrm{NS}_{\mathrm{n}}}{\mathrm{N}_{\mathrm{sr}}-1}\right\} \times \mathrm{rnd}
$$

The Equation (28) clearly depicts a lower value of for the solutions having better fitness values and a relatively higher value of $\varepsilon$ for the solutions having poor fitness values. Meaning, that the rivers having more number of streams have lower probability to evaporate compared to those having lesser number of streams. Therefore, one more evaporation condition for those rivers having fewer streams has to be satisfied to perform the raining process again. These conditions are:

Case $3 \exp \left(\frac{- \text { Iteration No }}{\text { MaxIteration }}\right)<$ rnd and $\mathrm{NS}_{\mathrm{x}}<\varepsilon$

If the above conditions in Case 3 are satisfied, then the raining process is started again using Equation (25). If the evaporation condition is satisfied for any river, then that specific river along with its streams will be removed and new streams and a river will be created but in a different position.

\section{IMPLEMENTATION OF WCA-ER FOR THE SOLUTION OF EEPSHES}

\subsection{Initialization}

The structure of solution for the hydro-thermal scheduling problem consists of two control variables; the discharge of water for hydropower plants and power generation by thermal plants. Both the variables are initialized within their prescribed limits as:

$$
\begin{aligned}
& D_{\text {hyt }}=D_{\text {hy }}^{\min }+\operatorname{rnd} \times\left(D_{\text {hy }}^{\text {max }}-D_{\text {hy }}^{\text {min }}\right) \\
& \mathrm{PG}_{\mathrm{sxt}}=\mathrm{PG}_{\mathrm{sx}}^{\mathrm{min}}+\operatorname{rnd} \times\left(\mathrm{PG}_{\mathrm{sx}}^{\max }-\mathrm{D}_{\mathrm{sx}}^{\min }\right)
\end{aligned}
$$


where, rnd is the random number generated in $(0,1)$. A candidate population of streams will be initialized as:

$\mathrm{X}_{\mathrm{kt}}=\left(\begin{array}{cccccccc}\mathrm{D}_{\mathrm{h} 1}^{1} & \mathrm{D}_{\mathrm{h} 2}^{1} & \mathrm{D}_{\mathrm{hj}}^{1} & \mathrm{D}_{\mathrm{hN}}^{1} ; & \mathrm{PG}_{\mathrm{s} 1}^{1} & \mathrm{PG}_{\mathrm{s} 2}^{1} & \mathrm{PG}_{\mathrm{si}}^{1} & \mathrm{PG}_{\mathrm{sN}_{\mathrm{s}}}^{1} \\ \mathrm{D}_{\mathrm{h}}^{2} & \mathrm{D}_{\mathrm{h} 2}^{2} & \mathrm{D}_{\mathrm{hj}}^{2} & \mathrm{D}_{\mathrm{hN}}^{2} ; & \mathrm{PG}_{\mathrm{s1}}^{2} & \mathrm{PG}_{\mathrm{s} 2}^{2} & \mathrm{PG}_{\mathrm{si}}^{2} & \mathrm{PG}_{\mathrm{sis}}^{2} \\ \mathrm{D}_{\mathrm{h} 1}^{\mathrm{t}} & \mathrm{D}_{\mathrm{h} 2}^{\mathrm{t}} & \mathrm{D}_{\mathrm{hj}}^{\mathrm{t}} & \mathrm{D}_{\mathrm{hN}}^{\mathrm{t}} ; & \mathrm{PG}_{\mathrm{s}}^{\mathrm{t}} & \mathrm{PG}_{\mathrm{s}}^{\mathrm{t}} & \mathrm{PG}_{\mathrm{s} 2}^{\mathrm{t}} & \mathrm{PG}_{\mathrm{sN}_{\mathrm{s}}}^{\mathrm{t}} \\ \mathrm{D}_{\mathrm{h} 1}^{\mathrm{M}} & \mathrm{D}_{\mathrm{h} 2}^{\mathrm{M}} & \mathrm{D}_{\mathrm{hj}}^{\mathrm{M}} & \mathrm{D}_{\mathrm{hN}}^{\mathrm{M}} ; & \mathrm{PG}_{\mathrm{s} 1}^{\mathrm{M}} & \mathrm{PG}_{\mathrm{s} 2}^{\mathrm{M}} & \mathrm{PG}_{\mathrm{s} 2}^{\mathrm{M}} & \mathrm{PG}_{\mathrm{sN}_{\mathrm{s}}}^{\mathrm{M}}\end{array}\right)$

where, $\mathrm{X}_{\mathrm{k}}$ is the kth stream or candidate solution.

\subsection{Constraint Handling}

Hydrothermal scheduling problem is more convoluted due to the involvement of many equality and inequality constraints. And, the fulfillment of all these constraints is very important and tedious task in this problem. In the proposed technique, pragmatic set of rules have been developed to fulfill these constraints.

\subsubsection{Constraint Handling for Inequality Constraints}

New streams are created after the raining process, which may violate the limits. If any stream candidate violates its limits, then the Equation (32) is used to clamp it.

$$
\begin{aligned}
& P_{\mathrm{sxt}}=\left\{\begin{array}{l}
\mathrm{PG}_{\mathrm{sx}}^{\min } \text { if } \mathrm{PG}_{\mathrm{sxt}}<\mathrm{PG}_{\mathrm{sx}}^{\min } \\
\mathrm{PG}_{\mathrm{sx}}^{\mathrm{max}} \text { if } \mathrm{PG}_{\mathrm{sxt}}<\mathrm{PG}_{\mathrm{sx}}^{\max }
\end{array}\right. \\
& D_{\text {hyt }}=\left\{\begin{array}{l}
D_{\text {hy }}^{\text {min }} \text { if } D_{\text {hyt }}<D_{\text {hy }}^{\text {min }} \\
D_{\text {hy }}^{\text {max }} \text { if } D_{\text {hyt }}<D_{\text {hy }}^{\max }
\end{array}\right.
\end{aligned}
$$

\subsubsection{Constraint Handling for Equality Constraints}

The equality constraints are more convoluted to be handled problem. The water balance constraint and power balance constraint are required to be handled after the initialization and every time whenever the raining process starts. A pragmatic method to balance these constraints is devised as follows:

\subsubsection{Water Balance Constraint Handling}

To meet exactly the limits on reservoir storage as per Equation (10) the water discharge rate of the yth hydro plant $\mathrm{D}_{\text {hyj }}$ in the dependent interval $\mathrm{j}$ is then calculated by:

$$
\left.\mathrm{D}_{\mathrm{hyj}}=\mathrm{U}_{\mathrm{hyO}}-\mathrm{U}_{\mathrm{hyM}}-\sum_{\substack{t=1 \\ t \neq 1}}^{\mathrm{M}} \mathrm{D}_{\mathrm{hyt}}-\sum_{\mathrm{t}=1 \mathrm{~m}=1}^{\mathrm{M}_{\mathrm{wj}}} \sum_{\mathrm{hm}, \mathrm{t}-\tau \mathrm{my}}\right)+\sum_{\mathrm{t}=1}^{\mathrm{M}} \ln \mathrm{F}_{\mathrm{hyt}}
$$

If the discharge violates the constraint, then it is attuned according to Equation (33) and another random interval is selected. The practice reiterates until the discharge fulfills the constraint.

\subsubsection{Power Balance Constraint Handling}

To fulfill the power balance constraint exactly as per Equation (4), the dependent thermal unit $j$ from the thermal plants is randomly selected and dependent thermal generation $\mathrm{PG}_{\mathrm{s}, \mathrm{j}}^{\mathrm{t}}$ is calculated using the following Equation (34):

$$
P G_{s, j}^{t}=P D^{t}-\sum_{y=1}^{N_{h}} P G_{h, y}^{t}-\sum_{\substack{i=1 \\ i \neq j}}^{N_{s}} P G_{s, i}^{t}
$$

The Equation (34) step is reiterated if the dependent thermal power generation does not fulfill the inequality constraint described in Equation (6). The dependent thermal unit is not selected again while selecting a new random thermal unit.

\subsection{Flowchart of Proposed WCA-ER for EEPSHES Problem}

The detailed flowchart of the proposed WCA-ER for EEPSHES problem is shown in Fig. (2).

\section{SIMULATION RESULTS}

The EEPSHES problem has been mapped as per proposed WCA-ER algorithm in Microsoft Visual $\mathrm{C}++6.0$ 
Environment runs on a Dual Core $1.2 \mathrm{GHz}$ Personal Computer. The efficacy of proposed algorithm is validated through its successful application on illustrative hydrothermal test system involving four cascaded hydropower plants and three thermal plants with nonlinear and non-smooth characteristics. The scheduling horizon is taken as 24 hour with 1 hour time interval. The time delay effect of hydropower reservoirs and valvepoint effect of thermal plants is also considered in this system. The hydropower sub-system configuration, hydropower unit generating coefficients, water discharge limits, reservoir volume limits, reservoir inflows, hourly power demand, generation limits and thermal machine fuel cost and emission coefficients were taken from [18].It can be seen from all the references given and many other available in the literature that this is a standard hydrothermal emission scheduling test system which is being used by all the researchers. The detail such as nature of the fuel and type of the plant used is not available in the literature. However, it is stated that as this system is
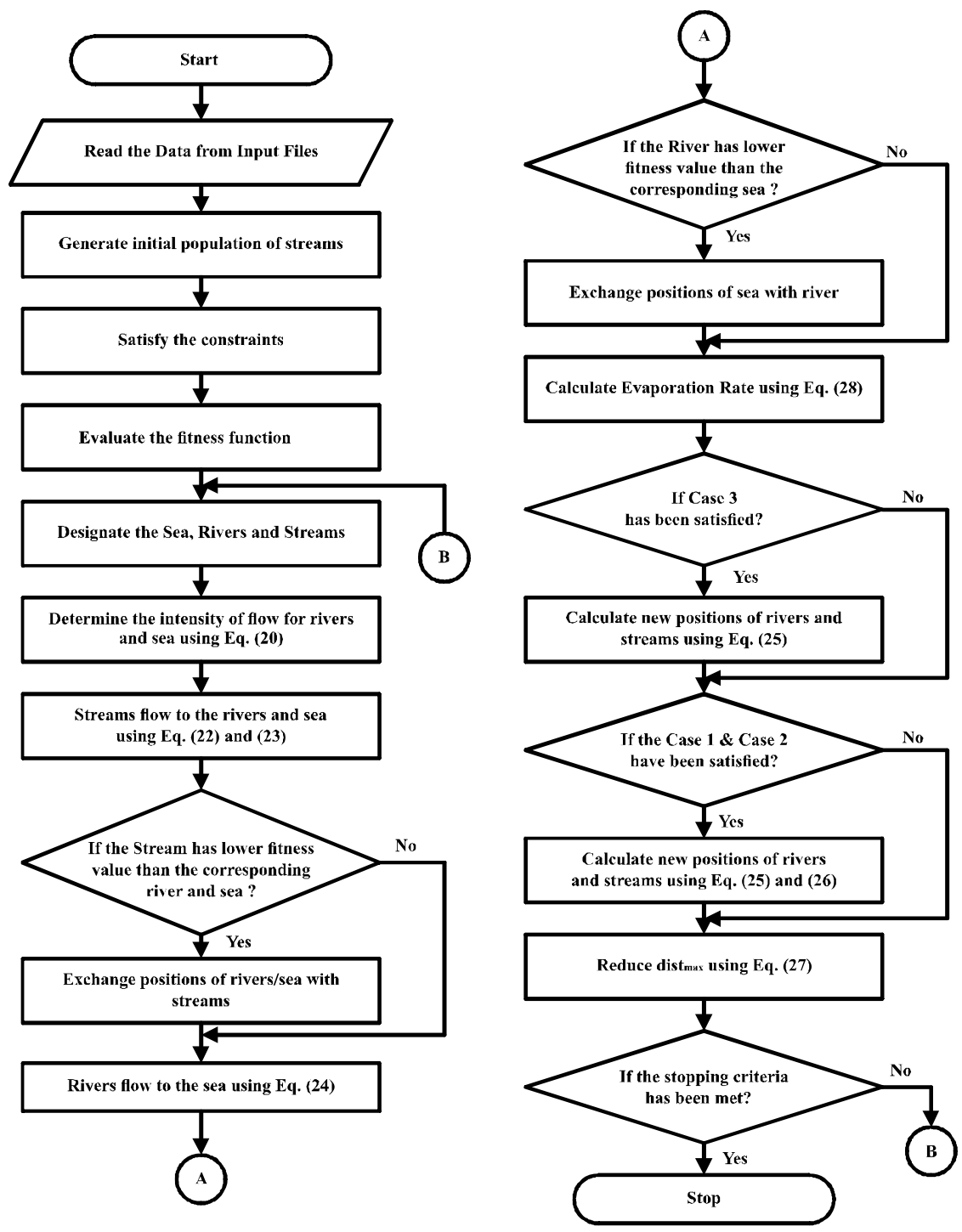

FIG. 2. FLOWCHART OF THE PROPOSED WCA-ER FOR EEPSHES

Mehran University Research Journal of Engineering \& Technology, Volume 36, No. 2, April, 2017 [p-ISSN: 0254-7821, e-ISSN: 2413-7219] 
to investigate the hydrothermal scheduling problem with reference to environment so it may be concluded that these fuel cost curves and fuel emission curves have been derived for the non-environment friendly fuels which may be coal, oil or gas. These exhaust gas emissions contain all of the $\mathrm{SO}_{\mathrm{x}}$ (Sulfur Oxides), $\mathrm{NO}_{\mathrm{x}}$ (Nitrogen Oxides) and $\mathrm{CO}_{2}$ (Carbon Dioxide).

The evolutionary model for control parameters of WCAER is shown in Table 1. This system has been solved for following three cases: (i) ECS, (ii) EES (iii) ECES.

\subsection{Case Study-1 (Economic Cost Scheduling)}

In this case the only fuel cost objective as per Equation (7) is considered. Here the objective is to only curtail the fuel cost of thermal plants. The value of weight factors in this case will be $\mathrm{K}_{1}=1, \mathrm{~K}_{2}=0$. For satisfaction of active power balance constraint, the priority list of thermal plants is same over the whole scheduling horizon in this case. Table 2 shows the optimal discharges of hydropower plants. Table 3 shows the hourly optimal hydropower and thermal power schedules obtained from proposed WCA-ER method.

TABLE 1. EVOLUTIONARY MODEL OF WCA-ER FOR EEPSHES

\begin{tabular}{|c|c|c|c|c|}
\hline Test System & Npop & Nsr & distmax & Iteration Count \\
\hline ECS & 200 & 16 & 0.01 & 500 \\
\hline EES & 200 & 16 & 0.01 & 500 \\
\hline ECES & 200 & 16 & 0.01 & 500 \\
\hline
\end{tabular}

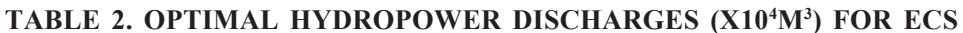

\begin{tabular}{|c|c|c|c|c|}
\hline Hour & Dh1 & $\mathrm{Dh} 2$ & $\mathrm{Dh} 3$ & $\mathrm{Dh} 4$ \\
\hline 1 & 6.1046 & 8.1792 & 29.6402 & 9.1269 \\
\hline 2 & 5.4318 & 6.1949 & 29.9045 & 6.3594 \\
\hline 3 & 5.9362 & 6.7230 & 30.0000 & 6.2664 \\
\hline 4 & 8.9485 & 7.4538 & 29.9646 & 8.3694 \\
\hline 5 & 8.4847 & 6.5939 & 13.2366 & 6.0991 \\
\hline 6 & 11.0949 & 7.2175 & 28.3448 & 8.8944 \\
\hline 7 & 12.7148 & 10.2435 & 26.2268 & 11.3994 \\
\hline 8 & 6.5577 & 7.6731 & 14.6733 & 9.3565 \\
\hline 9 & 7.6597 & 10.6396 & 15.6895 & 14.0828 \\
\hline 10 & 8.1283 & 11.7518 & 11.7939 & 11.0585 \\
\hline 11 & 7.4684 & 7.3311 & 14.3385 & 14.7082 \\
\hline 12 & 6.6907 & 11.6322 & 14.7312 & 18.3573 \\
\hline 13 & 7.6446 & 6.4461 & 14.7778 & 15.4409 \\
\hline 14 & 5.4657 & 7.5652 & 10.8462 & 17.4978 \\
\hline 15 & 9.8851 & 9.1026 & 12.8334 & 19.8362 \\
\hline 16 & 8.6102 & 7.6774 & 17.0467 & 19.3362 \\
\hline 17 & 6.4993 & 8.0413 & 13.1449 & 19.9229 \\
\hline 18 & 5.7685 & 7.7920 & 10.6561 & 19.4905 \\
\hline 19 & 10.2888 & 8.9853 & 13.4212 & 19.9049 \\
\hline 20 & 8.1666 & 8.5522 & 11.1023 & 19.5773 \\
\hline 21 & 6.3243 & 6.4746 & 10.1603 & 16.5704 \\
\hline 22 & 10.9906 & 7.1757 & 15.4951 & 18.2782 \\
\hline 23 & 6.6369 & 9.2974 & 10.8587 & 19.8235 \\
\hline 24 & 13.4993 & 13.2565 & 10.5476 & 19.4153 \\
\hline
\end{tabular}

Mehran University Research Journal of Engineering \& Technology, Volume 36, No. 2, April, 2017 [p-ISSN: 0254-7821, e-ISSN: 2413-7219] 


\subsection{Case Study-2 (Economic Emission Scheduling)}

In this case the objective is to only curtail the exhaust gas emission of thermal plants. So, the value of weight factors will be $\mathrm{K}_{1}=0, \mathrm{~K}_{2}=1 / \mathrm{CPF}_{\mathrm{t}}$. In this case the priority sequence of thermal plants is also same for whole scheduled period for the satisfaction of active power balance constraint. Table 4 shows the optimal discharges of hydropower plants. Table 5 shows the hourly optimal hydropower and thermal power schedules obtained from proposed WCA-ER method.

TABLE 3. OPTIMAL POWER DISPATCH SCHEDULE (MW) FOR ECS

\begin{tabular}{|c|c|c|c|c|c|c|c|c|}
\hline Hour & PGh1 & PGh2 & PGh3 & PGh4 & PGs1 & PGs2 & PGs3 & PD \\
\hline 1 & 62.5916 & 62.9360 & 0.0000 & 164.8901 & 109.0528 & 211.0222 & 139.5074 & 750 \\
\hline 2 & 57.6515 & 51.3260 & 0.0000 & 127.2092 & 20.0000 & 296.2949 & 227.5183 & 780 \\
\hline 3 & 62.2573 & 56.2608 & 0.0000 & 121.4932 & 105.7809 & 214.0372 & 140.1707 & 700 \\
\hline 4 & 82.9467 & 61.9031 & 0.0000 & 138.4805 & 20.0000 & 296.6697 & 50.0000 & 650 \\
\hline 5 & 79.5589 & 57.0285 & 35.3947 & 133.4103 & 20.0000 & 294.6076 & 50.0000 & 670 \\
\hline 6 & 90.9213 & 61.0607 & 0.0000 & 187.4464 & 24.9484 & 295.3230 & 140.3003 & 800 \\
\hline 7 & 93.6945 & 75.2684 & 0.0000 & 232.0191 & 106.2708 & 213.1185 & 229.6286 & 950 \\
\hline 8 & 64.8552 & 61.0859 & 28.0119 & 221.5919 & 104.0478 & 210.7085 & 319.6987 & 1010 \\
\hline 9 & 73.2386 & 74.8742 & 28.1228 & 275.8178 & 107.0819 & 212.0705 & 318.7942 & 1090 \\
\hline 10 & 77.0507 & 77.3766 & 36.5121 & 252.9144 & 20.0000 & 297.2368 & 318.9095 & 1080 \\
\hline 11 & 73.7672 & 56.6824 & 34.8186 & 301.4146 & 20.0000 & 296.9785 & 316.3387 & 1100 \\
\hline 12 & 68.6662 & 75.5455 & 36.7244 & 333.0647 & 21.5489 & 295.4081 & 319.0421 & 1150 \\
\hline 13 & 76.2520 & 49.6066 & 40.1356 & 306.8277 & 20.0000 & 298.7931 & 318.3850 & 1110 \\
\hline 14 & 59.3883 & 57.7272 & 44.6915 & 322.0130 & 20.0001 & 297.2280 & 228.9519 & 1030 \\
\hline 15 & 91.4095 & 66.3617 & 47.9707 & 335.8885 & 106.7111 & 213.3353 & 148.3232 & 1010 \\
\hline 16 & 84.0363 & 58.5501 & 39.6388 & 328.5988 & 106.8735 & 212.9762 & 229.3262 & 1060 \\
\hline 17 & 68.5625 & 60.0439 & 48.8339 & 328.2519 & 20.0001 & 297.8831 & 226.4246 & 1050 \\
\hline 18 & 62.2417 & 57.4056 & 50.8222 & 317.6560 & 20.0000 & 297.0922 & 314.7824 & 1120 \\
\hline 19 & 93.9813 & 62.7142 & 51.9487 & 313.6660 & 20.4656 & 297.9737 & 229.2506 & 1070 \\
\hline 20 & 80.9972 & 60.0253 & 52.6079 & 309.1548 & 105.1973 & 212.6637 & 229.3537 & 1050 \\
\hline 21 & 66.9973 & 49.0437 & 53.6533 & 284.2017 & 20.0000 & 298.4888 & 137.6153 & 910 \\
\hline 22 & 96.5056 & 54.7913 & 54.4432 & 289.6595 & 20.0000 & 294.6003 & 50.0000 & 860 \\
\hline 23 & 69.5485 & 66.0263 & 56.2835 & 292.6704 & 20.0000 & 295.4713 & 50.0000 & 850 \\
\hline 24 & 104.5733 & 77.3356 & 56.9995 & 281.1480 & 20.0000 & 209.9435 & 50.0000 & 800 \\
\hline \multicolumn{7}{|c|}{ Total Fuel Cost } & $\$ 40,906.20$ & \\
\hline \multicolumn{7}{|c|}{ Total Fuel Emission } & $26,060.02 \mathrm{lb}$ & \\
\hline
\end{tabular}




\subsection{Case Study-3 (Economic Cost \& Emission Scheduling)}

In this case an amalgamated objective function with attempt to optimize both fuel cost and exhaust gas emission is engaged. The value of weight factors for this case is $\mathrm{K}_{1}$ $=1, \mathrm{~K}_{2}=1$. The optimal hydropower discharges and optimal hourly dispatch schedules of hydropower and thermal plants for this case study are presented in Tables 6-7 respectively.

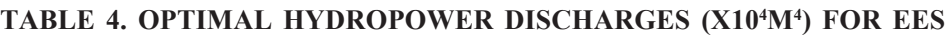

\begin{tabular}{|c|c|c|c|c|}
\hline Hour & Dh1 & $\mathrm{Dh} 2$ & $\mathrm{Dh} 3$ & $\mathrm{Dh} 4$ \\
\hline 1 & 8.2892 & 7.1573 & 30.0000 & 6.1427 \\
\hline 2 & 6.1844 & 7.5938 & 29.9964 & 6.1544 \\
\hline 3 & 9.5081 & 6.1081 & 29.9820 & 6.0450 \\
\hline 4 & 5.9062 & 6.2439 & 29.9629 & 6.0717 \\
\hline 5 & 7.8051 & 6.7318 & 29.9703 & 6.0741 \\
\hline 6 & 8.9871 & 6.2913 & 29.9922 & 8.0334 \\
\hline 7 & 11.8804 & 8.0337 & 29.7577 & 11.5543 \\
\hline 8 & 9.7033 & 8.1483 & 13.4735 & 13.3032 \\
\hline 9 & 8.2713 & 10.7655 & 14.8042 & 14.6578 \\
\hline 10 & 8.3964 & 6.8008 & 11.1870 & 15.8722 \\
\hline 11 & 8.9473 & 7.4121 & 15.9622 & 17.6727 \\
\hline 12 & 9.3741 & 11.3317 & 12.8390 & 19.9830 \\
\hline 13 & 11.8918 & 7.9828 & 11.4521 & 16.7531 \\
\hline 14 & 8.3741 & 7.7955 & 12.6205 & 17.0243 \\
\hline 15 & 7.4581 & 7.5702 & 14.2190 & 17.1806 \\
\hline 16 & 10.5005 & 7.5293 & 12.7237 & 18.1009 \\
\hline 17 & 5.8814 & 11.5377 & 10.9849 & 19.6596 \\
\hline 18 & 9.6708 & 10.9204 & 11.3354 & 19.8057 \\
\hline 19 & 5.4946 & 11.2345 & 10.6427 & 19.9033 \\
\hline 20 & 7.9418 & 9.5109 & 10.6822 & 19.4710 \\
\hline 21 & 6.4736 & 10.1611 & 11.3976 & 20.0000 \\
\hline 22 & 6.2181 & 9.7637 & 10.5932 & 19.9931 \\
\hline 23 & 6.6165 & 7.0792 & 11.7861 & 19.9881 \\
\hline 24 & 5.2260 & 8.2962 & 15.9536 & 19.9438 \\
\hline
\end{tabular}

Mehran University Research Journal of Engineering \& Technology, Volume 36, No. 2, April, 2017 [p-ISSN: 0254-7821, e-ISSN: 2413-7219] 
The fuel cost and exhaust gas emissions for the above three studies have been collectively summarized in Table 8. In Table 8, the second and third column are of ECS, in which the objective function is to minimize only the fuel cost without considering fuel emissions. However, fuel emissions are written against the fuel costs. In this case, the minimum generation cost is achieved by WCA-ER but the amount of exhaust gas emission is higher than EES and ECES because emissions are not considered here, while they are just written against the fuel cost.

TABLE 5. OPTIMAL POWER DISPATCH SCHEDULE (MW) FOR EES

\begin{tabular}{|c|c|c|c|c|c|c|c|c|}
\hline Hour & PGh1 & PGh2 & PGh3 & PGh4 & PGs1 & PGs2 & PGs3 & PD \\
\hline 1 & 77.4165 & 57.3241 & 0.0000 & 130.8086 & 169.6770 & 204.3197 & 110.4541 & 750 \\
\hline 2 & 63.3586 & 60.3145 & 0.0000 & 127.5194 & 175.0000 & 263.1649 & 90.6425 & 780 \\
\hline 3 & 84.6393 & 52.1450 & 0.0000 & 121.8944 & 170.6317 & 187.0569 & 83.6328 & 700 \\
\hline 4 & 61.0339 & 54.6181 & 0.0000 & 116.3476 & 174.9603 & 167.2592 & 75.7809 & 650 \\
\hline 5 & 74.5366 & 58.6755 & 0.0000 & 138.3407 & 154.9486 & 177.6646 & 65.8341 & 670 \\
\hline 6 & 81.0147 & 56.0022 & 0.0000 & 182.1817 & 174.9796 & 240.0116 & 65.8102 & 800 \\
\hline 7 & 91.6290 & 66.2558 & 0.0000 & 239.0626 & 175.0000 & 293.3554 & 84.6972 & 950 \\
\hline 8 & 83.0248 & 66.2805 & 19.1151 & 270.4206 & 175.0000 & 286.3440 & 109.8149 & 1010 \\
\hline 9 & 75.9847 & 77.9235 & 18.7092 & 294.9102 & 175.0000 & 299.9667 & 147.5058 & 1090 \\
\hline 10 & 77.5647 & 57.4739 & 27.3226 & 315.8865 & 174.8895 & 299.7609 & 127.1020 & 1080 \\
\hline 11 & 81.6762 & 62.3506 & 20.3942 & 340.0158 & 174.9758 & 296.1606 & 124.4268 & 1100 \\
\hline 12 & 84.1762 & 80.5469 & 30.8842 & 355.1892 & 174.9849 & 285.7449 & 138.4737 & 1150 \\
\hline 13 & 94.3549 & 63.9588 & 35.3134 & 326.5635 & 174.9590 & 300.0000 & 114.8505 & 1110 \\
\hline 14 & 79.2513 & 63.5360 & 37.8243 & 325.4940 & 173.3511 & 275.9804 & 74.5630 & 1030 \\
\hline 15 & 74.0154 & 62.9649 & 40.9218 & 326.1293 & 174.9976 & 232.5274 & 98.4437 & 1010 \\
\hline 16 & 91.3872 & 62.9736 & 44.5163 & 330.5286 & 174.9952 & 275.3578 & 80.2414 & 1060 \\
\hline 17 & 62.2482 & 80.4255 & 46.4973 & 336.3676 & 174.9701 & 275.0770 & 74.4144 & 1050 \\
\hline 18 & 87.7757 & 74.6755 & 49.3178 & 331.4999 & 175.0000 & 299.8722 & 101.8589 & 1120 \\
\hline 19 & 58.9007 & 72.9324 & 49.8259 & 327.2611 & 174.8971 & 292.8554 & 93.3274 & 1070 \\
\hline 20 & 77.4292 & 64.3356 & 52.7274 & 318.3589 & 174.9888 & 281.0945 & 81.0657 & 1050 \\
\hline 21 & 66.8533 & 66.5272 & 54.9978 & 313.2516 & 142.0689 & 187.2672 & 79.0340 & 910 \\
\hline 22 & 65.0695 & 64.1528 & 56.1513 & 304.5324 & 160.7682 & 140.4382 & 68.8877 & 860 \\
\hline 23 & 68.5899 & 50.0538 & 58.3878 & 294.6336 & 157.9677 & 156.3675 & 63.9997 & 850 \\
\hline 24 & 57.1230 & 57.0766 & 56.6192 & 284.0968 & 164.1044 & 130.9800 & 50.0000 & 800 \\
\hline \multicolumn{7}{|c|}{ Total Fuel Cost } & $\$ 47,114.98$ & \\
\hline \multicolumn{7}{|c|}{ Total Fuel Emission } & $16,342.68 \mathrm{lb}$ & \\
\hline
\end{tabular}


The next two columns in Table 8 are of EES, in which the objective function is to minimize the fuel emissions only without considering the fuel cost. It can be seen that, in EES the lowest fuel emissions are reported by the WCAER method as compared to other methods but the fuel cost is higher than ECS and ECES and are just written against the fuel emissions.
The last two columns of Table 8 are of ECES. In this case both the minimization of fuel cost and fuel emissions has been taken into account in the objective function. Even then the fuel costs and fuel emissions obtained by WCAER are found to be lowest. However, they are a bit higher than the independent cases ECS and EES indicating that cost is compromised when both conflicting objective

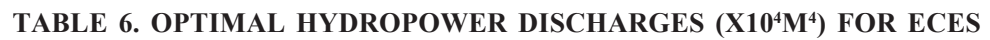

\begin{tabular}{|c|c|c|c|c|}
\hline Hour & Dh1 & $\mathrm{Dh} 2$ & $\mathrm{Dh} 3$ & $\mathrm{Dh} 4$ \\
\hline 1 & 11.8477 & 7.8645 & 29.8337 & 8.8081 \\
\hline 2 & 9.7614 & 6.4216 & 29.9254 & 6.6301 \\
\hline 3 & 7.3465 & 6.8108 & 29.5547 & 7.7086 \\
\hline 4 & 5.0346 & 6.0861 & 29.9979 & 6.0000 \\
\hline 5 & 5.0002 & 6.0197 & 29.7788 & 6.0039 \\
\hline 6 & 6.6406 & 6.0787 & 27.5871 & 6.6368 \\
\hline 7 & 9.4176 & 6.1248 & 13.7483 & 12.1122 \\
\hline 8 & 6.3226 & 8.2604 & 28.8344 & 12.8459 \\
\hline 9 & 8.9206 & 8.1707 & 29.5721 & 19.0626 \\
\hline 10 & 5.5079 & 9.0175 & 13.0337 & 17.2788 \\
\hline 11 & 8.7025 & 7.3063 & 10.5288 & 17.4190 \\
\hline 12 & 11.5746 & 11.0684 & 10.8081 & 18.5341 \\
\hline 13 & 9.8954 & 7.0877 & 11.0316 & 15.6308 \\
\hline 14 & 9.7404 & 6.1881 & 10.5982 & 19.6879 \\
\hline 15 & 5.8829 & 7.6665 & 13.9850 & 18.1857 \\
\hline 16 & 8.8551 & 10.9819 & 10.9441 & 19.9846 \\
\hline 17 & 11.0504 & 11.4869 & 10.2679 & 19.5272 \\
\hline 18 & 12.7296 & 12.3343 & 13.1010 & 14.6610 \\
\hline 19 & 5.7172 & 7.0117 & 10.0000 & 15.9939 \\
\hline 20 & 8.4717 & 13.9244 & 10.4492 & 19.6782 \\
\hline 21 & 7.0936 & 6.7326 & 10.7557 & 18.0715 \\
\hline 22 & 8.3570 & 9.7133 & 10.5697 & 19.9892 \\
\hline 23 & 6.0833 & 12.1771 & 10.1605 & 19.9915 \\
\hline 24 & 5.0465 & 7.4661 & 13.7478 & 19.9384 \\
\hline
\end{tabular}

Mehran University Research Journal of Engineering \& Technology, Volume 36, No. 2, April, 2017 [p-ISSN: 0254-7821, e-ISSN: 2413-7219] 
functions; cost and emissions are taken into account in case of ECES.

The results of proposed WCA-ER method have been compared with the results obtained by PSO [19], IQPSO
[20], DE [13], QADEVT [21] and SOHPSO_TVAC [22] in Table 8 . The results clearly depict the superiority of WCA-ER over others in terms of reduction in both of the fuel cost and exhaust gas emission for all of the three cases.

TABLE 7. OPTIMAL POWER DISPATCH SCHEDULE (MW) FOR ECES

\begin{tabular}{|c|c|c|c|c|c|c|c|c|}
\hline Hour & PGh1 & PGh2 & PGh3 & PGh4 & PGs1 & PGs2 & PGs3 & PD \\
\hline 1 & 92.2835 & 61.2789 & 0.0000 & 161.5378 & 175.0000 & 209.8999 & 50.0000 & 750 \\
\hline 2 & 83.9295 & 52.9503 & 0.0000 & 130.7568 & 175.0000 & 213.7197 & 123.6436 & 780 \\
\hline 3 & 70.2721 & 56.8486 & 0.0000 & 138.1021 & 175.0000 & 209.7773 & 50.0000 & 700 \\
\hline 4 & 52.8063 & 53.4541 & 0.0000 & 110.6720 & 175.0000 & 208.0676 & 50.0000 & 650 \\
\hline 5 & 52.7099 & 54.0229 & 0.0000 & 133.2345 & 174.9997 & 205.0330 & 50.0000 & 670 \\
\hline 6 & 66.1535 & 54.9245 & 0.0000 & 160.7973 & 174.9807 & 210.0118 & 133.1321 & 800 \\
\hline 7 & 83.1620 & 55.1915 & 27.1130 & 241.7891 & 175.0000 & 230.5984 & 137.1461 & 950 \\
\hline 8 & 64.0315 & 68.4376 & 0.0000 & 262.6696 & 175.0000 & 300.0000 & 139.8614 & 1010 \\
\hline 9 & 81.7027 & 67.8134 & 0.0000 & 327.3859 & 174.9857 & 300.0000 & 138.1123 & 1090 \\
\hline 10 & 58.5782 & 72.6016 & 14.0367 & 320.9319 & 175.0000 & 299.7596 & 139.0919 & 1080 \\
\hline 11 & 82.6814 & 63.3734 & 20.1594 & 319.5060 & 175.0000 & 299.4337 & 139.8461 & 1100 \\
\hline 12 & 96.1490 & 81.6052 & 22.5983 & 336.1228 & 174.9773 & 299.4256 & 139.1217 & 1150 \\
\hline 13 & 89.1990 & 60.7897 & 27.7293 & 318.0563 & 175.0000 & 300.0000 & 139.2257 & 1110 \\
\hline 14 & 88.9525 & 56.1060 & 32.6952 & 350.2104 & 175.0000 & 277.0036 & 50.0323 & 1030 \\
\hline 15 & 62.9492 & 66.7138 & 34.9549 & 333.0080 & 174.9822 & 211.7535 & 125.6385 & 1010 \\
\hline 16 & 85.1011 & 82.4932 & 39.9292 & 339.9034 & 174.9999 & 287.5732 & 50.0000 & 1060 \\
\hline 17 & 96.1739 & 81.7800 & 40.8876 & 329.8001 & 174.9983 & 276.3602 & 50.0000 & 1050 \\
\hline 18 & 100.7150 & 80.5682 & 42.9325 & 285.5166 & 174.9982 & 299.1425 & 136.1271 & 1120 \\
\hline 19 & 61.1285 & 54.6581 & 46.4879 & 296.6213 & 174.9138 & 299.0319 & 137.1585 & 1070 \\
\hline 20 & 81.2763 & 80.5664 & 50.9815 & 317.7929 & 174.9781 & 217.4038 & 127.0011 & 1050 \\
\hline 21 & 71.8345 & 50.5211 & 53.5129 & 299.4736 & 174.9775 & 209.6805 & 50.0000 & 910 \\
\hline 22 & 80.4593 & 66.9617 & 54.7225 & 305.4059 & 174.9806 & 127.4701 & 50.0000 & 860 \\
\hline 23 & 64.2379 & 73.7756 & 56.1522 & 294.8998 & 175.0000 & 135.9346 & 50.0000 & 850 \\
\hline 24 & 55.4564 & 52.2444 & 58.8921 & 284.0673 & 175.0000 & 124.3398 & 50.0000 & 800 \\
\hline \multicolumn{7}{|c|}{ Total Fuel Cost } & $\$ 42,835.21$ & \\
\hline \multicolumn{7}{|c|}{ Total Fuel Emission } & $16,755.60 \mathrm{lbb}$ & \\
\hline
\end{tabular}




\begin{tabular}{|c|c|c|c|c|c|c|}
\hline \multirow{2}{*}{ Methods } & \multicolumn{2}{|c|}{ ECS } & \multicolumn{2}{|c|}{ EES } & \multicolumn{2}{|c|}{ ECES } \\
\hline & $\begin{array}{l}\text { Fuel Cost } \\
\text { (\$) }\end{array}$ & $\begin{array}{l}\text { Fuel Emission } \\
\text { (lb) }\end{array}$ & $\begin{array}{l}\text { Fuel Cost } \\
\text { (\$) }\end{array}$ & $\begin{array}{l}\text { Fuel Emission } \\
\text { (b) }\end{array}$ & $\begin{array}{l}\text { Fuel Cost } \\
\qquad(\$)\end{array}$ & $\begin{array}{l}\text { uel Emission } \\
\text { (lb) }\end{array}$ \\
\hline Proposed WCA-ER & $40,906.20$ & $26,060.02$ & $47,114.98$ & $16,342.68$ & $42,835.21$ & $16,755.60$ \\
\hline PSO [19] & 42,474 & 28,132 & 48,263 & 16,928 & 43,280 & 17,899 \\
\hline IQPSO [20] & 42,359 & 31,298 & 45,271 & 17,767 & 44,259 & 18,229 \\
\hline $\mathrm{DE}[13]$ & 43,500 & 21,092 & 51,449 & 18,257 & 44,914 & 19,615 \\
\hline QADEVT[21] & 42,587 & 30,786 & 46,100 & 17,535 & 43,395 & 18,234 \\
\hline SOHPSO_TVAC[22] & 41,983 & 24,482 & 44,432 & 16,803 & 43,045 & 17,003 \\
\hline
\end{tabular}

\section{CONCLUSION}

Short term EEPSHES is of significant importance in today's power system operation. In this paper, a new meta-heuristic naming WCA-ER has been applied to solve the multi-objective problem of short term EEPSHES. The combinatorial optimization problem of EEPSHES has been mapped according to the WCA-ER and all the constraints have been satisfied. The inequality and equality constraints have been handled by adopting some pragmatic rules. Then the efficacy of this technique has been investigated on a standard hydrothermal test system involving four cascaded hydropower plants and three thermal plants with three different cases. The simulation results reveal that the proposed technique has strength in solving optimally both fuel cost and exhaust gas emission scheduling. The cost obtained for ECS is lowest and the emissions obtained in EES are lowest but for the combined case of ECES, which is a multi-objective optimization problem of two conflicting objectives, a compromise between the fuel costs and fuel emissions has been obtained, which is also optimum as compared to other strong techniques in the literature. Therefore, the proposed
WCA-ER algorithm is an effective method to find an optimal solution for the multi-objective EEPSHES problem.

\section{ACKNOWLEDGEMENT}

The authors gratefully acknowledge the University of Engineering \& Technology, Taxila, Pakistan, for providing support to carry out this research work.

\section{REFERENCES}

[1] Ahmad, A., and Asar, A. "A PSO Based Artificial Neural Network Approach for Short Term Unit Commitment Problem", Mehran University Research Journal of Engineering \& Technology, Volume 29, pp. 607-20, Jamshoro, Pakistan, 2010.

[2] Malik, T., and Asar, A., "Neuro-Genetic Hybrid Approach for the Solution of Non-Convex Economic Dispatch Problem", Mehran University Research Journal of Engineering \& Technology, Volume 28, pp. 289-302, Jamshoro, Pakistan, 2009.

[3] Malik, T.N., Zafar, S., and Haroon, S., “An Improved Chaotic Hybrid Differential Evolution for the ShortTerm Hydrothermal Scheduling Problem Considering Practical Constraints", Frontiers of Information Technology \& Electronic Engineering, Volume 16, pp. 404-17, 2015. 
[4] Talaq, J.H., El-Hawary, F., and El-Hawary, M.E., “A Summary of Environmental/Economic Dispatch Algorithms", IEEE Transactions on Power Systems, Volume 9, pp. 1508-16, 1994.

Huang, C.-M., Yang, H.-T., and Huang, C.-L. "BiObjective Power Dispatch using Fuzzy SatisfactionMaximizing Decision Approach", IEEE Transactions on Power Systems, Volume 12, pp. 1715-21, 1997.

[6] Kulkarni, S.A., and Kothari, D.P., "Combined Economic and Emission Dispatch using Improved Backpropagation Neural Network", Electric Machines \&Power Systems, Volume 28, pp. 31-44, 2000.

Abido, M., "Environmental/Economic Power Dispatch using Multiobjective Evolutionary Algorithms", IEEE Transactions on Power Systems, Volume 18, pp. 1529-37, 2003.

[11] Wang, L., and Singh, C., "Reserve-Constrained Multiarea Environmenta1/Economic Dispatch Based on Particle Swarm Optimization with Local Search", Engineering Applications of Artificial Intelligence, Volume 22, pp. 298-307, 2009.

[12] Lu, S., Sun, C., and Lu, Z., “An Improved QuantumBehaved Particle Swarm Optimization Method for ShortTerm Combined Economic Emission Hydrothermal Scheduling", Energy Conversion and Management, Volume 51, pp. 561-71, 2010.
[13] Mandal, K., and Chakraborty, N., "Short-Term Combined Economic Emission Scheduling of Hydrothermal Power Systems with Cascaded Reservoirs using Differential Evolution", Energy Conversion and Management, Volume 50, pp. 97-104, 2009.

[14] Glotiæ, A., and Zamuda, A., "Short-Term Combined Economic and Emission Hydrothermal Optimization by Surrogate Differential Evolution", Applied Energy, Volume 141, pp. 42-56, 2015.

[15] Li, C., Zhou, J., Lu, P., and Wang, C., "Short-Term Economic Environmental Hydrothermal Scheduling using Improved Multi-Objective Gravitational Search Algorithm”, Energy Conversion and Management, Volume 89, pp. 127-36, 2015.

[16] Tian, H., Yuan, X., Ji, B., and Chen, Z., "Multi-Objective Optimization of Short-Term Hydrothermal Scheduling using Non-Dominated Sorting Gravitational Search Algorithm with Chaotic Mutation”, Energy Conversion and Management, Volume 81, pp. 504-19, 2014.

[17] Sadollah, A., Eskandar, H., Bahreininejad, A., and Kim, J.H., "Water Cycle Algorithm with Evaporation Rate for Solving Constrained and Unconstrained Optimization Problems", Applied Soft Computing, Volume 30, pp. 58-71, 2015.

[18] Basu, M., "An Interactive Fuzzy Satisfying Method Based on Evolutionary Programming Technique for Multiobjective Short-Term Hydrothermal Scheduling", Electric Power Systems Research, Volume 69, pp. 277-85, 2004.

[19] Mandal, K., and Chakraborty, N., "Short-Term Combined Economic Emission Scheduling of Hydrothermal Systems with Cascaded Reservoirs using Particle Swarm Optimization Technique”, Applied Soft Computing, Volume 11, pp. 1295-302, 2011.

[20] Sun, C., and Lu, S., "Short-Term Combined Economic Emission Hydrothermal Scheduling using Improved Quantum-Behaved Particle Swarm Optimization”, Expert Systems with Applications, Volume 37, pp. 4232-41, 2010. 
[21] Lu, S., and Sun, C., "Quadratic Approximation Based Differential Evolution with Valuable Trade Off Approach for Bi-Objective Short-Term Hydrothermal Scheduling", Expert Systems with Applications, Volume 38, pp. 13950-60, 2011.
[22] Mandal, K.K., and Chakraborty, N., "Daily Combined Economic Emission Scheduling of Hydrothermal Systems with Cascaded Reservoirs using Self Organizing Hierarchical Particle Swarm Optimization Technique”, Expert Systems with Applications, Volume 39, pp. 3438-45, 2012. 